\title{
Curriculum Theory as Practiced: Case Studies of Operationalized Value Orientations
}

\author{
Catherine D. Ennis \\ University of Maryland
}

\begin{abstract}
This research was conducted to investigate the role of value orientations in effective elementary physical educators' curricular decision making. Educational value orientations served as the theoretical base for the research. Three research questions were examined: (a) what were the learning goals and expectations for student performance in each program, (b) why did teachers value these goals, and (c) how well did students understand the goals and expectations of the program? Data were collected through class observations, teacher and student interviews, and the Value Orientation Inventory. Data were analyzed using constant comparison. Results described students' learning goals and academic and social performance expectations within each teacher's value profile. Dynamical systems theory was used to elaborate the influence of value orientations in the curriculum decisionmaking process.
\end{abstract}

Value orientations represent philosophical beliefs operationalized as educational goals for student learning. Teachers' priorities for curricular decision making often reveal a balance among goals that reflect the learner's needs, contextual limitations, and knowledge requirements. Value orientations manifested as content strains (Kliebard, 1988) can be traced through the historical and theoretical curriculum literature (i.e., Eisner \& Vallance, 1974; McNeil, 1985). Theorists postulate that a teacher's value perspective influences the selection of particular content components, the relative emphasis each will receive in the instructional plan, and how well each will be mastered. In essence, value orientations are pervasive and appear to determine the characteristics of a physically educated person in various curricular perspectives.

Curriculum decision making as it is presented in articles, textbooks, and curriculum guides can be described within one or more value orientations. It is more difficult, however, to identify value orientations in educational settings because of the constant struggle among perspectives for credibility and resources (Kliebard, 1987). Compromises in curricular decision making often necessitate blending perspectives due to constraints in the environment. Thus, it is logical to assume that value orientations in operational settings should be represented as

Catherine D. Ennis is with the Department of Kinesiology at the University of Maryland, College Park, MD 20742-2611. 
the relative contribution or strength of each value perspective within the teacher's value profile.

Ennis and Hooper (1988) developed the Value Orientation Inventory (VOI) to examine physical education teachers' value profiles. Teachers rank items that describe the content, instructional strategies, tasks, and evaluation policies of five theoretical value orientations. Value profiles are derived from composite scores on each orientation. Although the VOI has been used to examine value profiles of large samples of teachers (i.e., Ennis \& Zhu, 1991), it is equally important to conduct detailed analyses of operational decision making in the classroom or gym.

The role of value orientations in elementary physical educators' curricular decision making was investigated in this research. Three teachers' physical education programs in a suburban Washington, D.C., school district were studied to determine the extent to which each teacher's curricular decisions reflected his or her value priorities. Specifically, three research questions were examined:

1. What were the learning goals and expectations for student performance in each program?

2. Why did teachers value these goals?

3. How well did students understand the goals and expectations of the program?

The significance of this research lies in the potential to understand curricular decision making within the parameters of theoretical value orientations. The nature and degree of learning in physical education may depend not only on instructional methods but also on how much the teacher values and emphasizes particular content components. This research is an investigation of a link between the planning-teaching process that may be of substantial importance in student learning.

\section{Value Orientations}

Five theoretical value perspectives blend in instructional settings to influence the educational beliefs that teachers bring to their classrooms. Value orientations reflected in curriculum strains wax and wane within the educational and political process (Kliebard, 1988). Kliebard (1988, p. 30) explained that " what emerges as a dominant strain in the curriculum is not a function of the force of a particular proposal alone but the interaction of curriculum ideas and sympathetic or antagonistic social conditions.' Curricular theorists have postulated these influential strains or value orientations: (a) disciplinary mastery, (b) self-actualization, (c) learning process, (d) social reconstruction, and (e) ecological integration.

Disciplinary mastery advocates emphasize the central role of the body of knowledge in the educational process (Brunner, 1960). Students are encouraged to understand the theoretical structure of the knowledge base and master factual information (McNeil, 1985). The contemporary perspective on disciplinary mastery originated in the work of Herbert Spencer. Spencer (1860) argued that the knowledge of most worth was science. He pointed out that students must master the scientific body of knowledge in order to make a productive contribution 
to society. In physical education, the scientific knowledge base is perceived to be firmly grounded in cognitive and performance mastery (Siedentop, Mand, \& Taggert, 1986). Definitions of a physically educated person according to the National Association for Sport and Physical Education (NASPE; Franck, 1991) include many disciplinary mastery learning goals; for example, the physically educated person "demonstrates competence in a variety of manipulative, locomotor and non-locomotor skills" and "assesses, achieves and maintains physical fitness." Disciplinary mastery is the dominant value orientation in the NASPE document, with more than half of the 20 outcomes representing performance and knowledge competence. When disciplinary mastery is a strong emphasis in teacher preparation programs, course work and teaching experiences are directed toward mastery of the theoretical knowledge base (e.g., exercise physiology, biomechanics). Effective teaching methods are necessary to convey the knowledge base appropriately to meet skill and fitness objectives (Rink, 1985).

Conversely, the self-actualization value orientation is described as a humanistic or child-centered approach to curriculum development (Kliebard, 1988). Maslow (1979) and Rogers (1983) elaborated the philosophical perspective and provided various counseling and teaching strategies for use in clinical settings. Self-actualization-oriented teachers select content that contributes to personal growth. Although skill, sport, and fitness-oriented curricula are often introduced in physical education as the means of achieving personal growth, sport proficiency and fitness are not perceived as the most important learning outcomes (Hellison, 1985). The self-actualization orientation is also included in the NASPE statement. For example, the physically educated person "understands that physical activity provides the opportunity for enjoyment, self-expression and communication" and "cherishes the feelings that result from regular participation in physical activity"' (Franck, 1991).

Learning process advocates teach students how to learn independently (Bloom, 1981; Papert, 1980). Active learners analyze tasks, refine performances, and decide how content can be used to solve relevant problems (Kilpatrick, 1918). In physical education, Lawson and Placek (1981) presented a learning process curriculum. Steinhardt (in press) incorporated the learning process orientation into adult fitness programming. The definition of the physically educated person provided by NASPE includes several statements reflecting the learning process orientation. For example, the physically educated person "has learned how to learn new skills," "designs safe, personal fitness programs in accordance with principles of training and conditioning," and "applies concepts and principles to the development of new skills" (Franck, 1991).

Social reconstruction advocates perceive the school as an arena for social change (Apple, 1982). Teachers with this value orientation help students to focus on economic, social, and political issues that shape opportunities for success (Freire, 1970). Students are encouraged to ask questions and develop strategies that contribute to classroom reform and promote access for all. In physical education, Dewar (1987) and Griffin (1985) encouraged educators to think reflectively about equity issues. Content associated with the social goals of cooperation and group membership appears to be important to middle and high school physical education teachers (Ennis, Chen, \& Ross, 1992). Social goals were also included in the NASPE statement: A physically educated person "recognizes that participation in physical activity can lead to multi-cultural and 
international understanding" and "appreciates the relationships with others that result from participation in physical activity" (Franck, 1991).

John Dewey (1916) articulated the ecological integration orientation as a balance of perspectives associated with the learner's needs, contextual opportunities and limitations, and knowledge demands. This perspective has been examined by Colwell (1985) and further elaborated by Jewett and Ennis (1990). Curricularists plan programs with a futuristic perspective and encourage students to integrate knowledge within a personally meaningful context. In physical education, Jewett and her colleagues (Jewett \& Bain, 1987; Jewett \& Mullan, 1977) used the ecological integration orientation as the theoretical foundation for the personal meaning curriculum approach. Although the multiple perspectives presented in the NASPE document represent the balanced curriculum perspective advocated in this orientation, ecological integration is also evident in specific statements; for example, the physically educated person "understands that wellness involves more than being physically fit" and "respects the role that regular physical activity plays in the pursuit of life-long health and well-being", (Franck, 1991).

Curriculum research by Ennis and her colleagues suggested that physical education teachers' value structures represent a blend of traditional value orientations. In most instances, physical educators consistently prioritize items representing content goals, instructional strategies, and learning tasks to reflect a high or low value orientation priority (Ennis \& Zhu, 1991). Findings from research (Ennis, Mueller, \& Hooper, 1990) with elementary physical educators indicated that social reconstruction teachers were more likely to share curricular decisions with their students than were disciplinary mastery teachers. Ennis, Ross, and Chen (1992) examined differences in high school physical education teachers' learning goals and expectations. They found that teachers displaying either a disciplinary mastery/learning process (DM/LP) or an ecological integration/social reconstruction (EI/SR) paired value orientation emphasized some learning goals more than others. DM/LP teachers articulated learning goals consistent with the development of skills and fitness; EI/SR teachers advocated curricula based on cooperation, enjoyment, and participation.

The current research was conducted to examine three elementary physical educators' operational curricular decisions. Data from observations, teacher and student interviews, and the VOI were used to examine curricular and instructional decisions to elaborate teachers' value profiles.

\section{Method}

\section{Subjects}

Three elementary physical educators and their students were participants in this study. The physical educators taught in a suburban school district (enrollment $=30,000$ ) in the metropolitan Washington, D.C., area. All teachers were white; two were male. Each had been teaching for at least 15 years. The teachers were selected based on supervisor recommendations and the following five criteria: (a) outstanding teaching award recipient, (b) cooperating teacher for two university teacher preparation programs, (c) strongly supported by principal, (d) involved in school-wide projects, and (e) well liked by the classroom teachers. 
Students in the school district were primarily white (80.4\%), with African American (13\%) and Asian (5.5\%) students as the most prominent minorities. Third- through fifth-grade students participated in classes examined in this research. They represented families with high, medium, and low incomes. Students participated in a multiactivity curriculum (Siedentop et al., 1986) three times a week for 45 minutes. Informed consent was received from both teachers and students.

\section{Data Collection}

Data were collected separately at the three schools through observation, teacher and student interviews, and the VOI. Data from field notes and from interview transcripts were collected to develop a qualitative value profile based on teachers' learning goals and rationale and students' comprehension. Field notes were taken by a nonparticipant observer who observed four third-, fourth-, and fifth-grade classes $(N=12)$ on a weekly basis for 8 weeks. The same four classes were observed in each program. Data were collected using a lap computer. The research questions served as the focus of the study. Specifically, the focus of the observations was to describe the content and methods used in each class. The observer recorded the rationale given by the teacher to students for content selection and how the content was implemented within each class. Students' responses to the teacher's directions and feedback were also noted. Narrative descriptions of class settings were developed to position the curriculum within the educational ecosystem. The observer sat inconspicuously at the side of the gym and did not interact with the teacher or the students.

A formal, structured format was used to collect data from the interviews after the observation period. The interview questions were open-ended and focused primarily on content selection, rationale, and student response. The questions were not developed based on specific value orientations, and care was taken not to lead the respondent toward a particular value perspective. Teachers were interviewed at their convenience, usually during their planning period. Questions focused on a description of their curricular goals and expectations, the rationale for their teaching strategies, and their expectations associated with evaluation and student behavior. Students were questioned during their physical education class about their curricular likes and dislikes, their perceptions about the learning goals, and their definitions of terms frequently used by the teacher (i.e., fitness, exercise, cooperation, and respect). Interviews were audiotaped and transcribed for analysis.

\section{Value Orientation Inventory}

Data from the Value Orientation Inventory were used to develop quantitative value profiles of the teachers. The VOI was developed by Ennis and Hooper (1988) to examine physical educators' priorities on the five value orientations. The inventory format uses ranked sets of items to encourage teachers to make curriculum decisions about what knowledge is of most worth. Although there are many content options at each grade level and within each unit, the limited amount of contact time allotted to physical education in the school schedule requires that teachers prioritize learning goals to reflect those of most importance. Because content alternatives often reflect difficult choices for decision makers, inventories 
that permit them to rate all items as positive and valuable, as in Likert formats, do not reflect the central problem in curriculum development-that of selecting the knowledge of most worth. Therefore, the VOI uses a ranking format to encourage physical educators to set priorities for content selection.

The inventory was described in detail by Ennis and Zhu (1991). Briefly, the VOI is a 75-item inventory, with 15 sets of 5 items. One item in each set reflects one of the five value orientations. Teachers rank their preferences for content, teaching strategies, and learning tasks as reflected in the value orientations. Items are unlabeled and placed randomly in the sets. The teacher ranks items from highest (1) to lowest (5) priority. The value profile represents a composite score from each orientation. Raw scores are converted to $T$ scores and divided, using a $.6 S D$, into high and low priorities. Because the inventory is based on a forced-choice format, the data are ipsative in nature and consistently violate the independence assumption (Hicks, 1970). In other words, once the subject has assigned an item the highest ranking, the remaining items are forced into other, less valued positions. Thus, data reflect relative findings, or the item rankings compared to others in the set.

\section{Data Analysis}

Constant comparison (Goetz \& LeCompte, 1984) was used to analyze field notes and interview transcripts. Constant comparison is a systematic four-step process that consists of (a) scanning the data to locate common categories, (b) identifying properties and common themes in the data, (c) comparing themes across data categories (triangulation), and (d) developing explanatory theory. In this study, field note and interview data were scanned individually to locate major categories associated with learning goals and expectations. In the second stage, properties and common themes were identified, and the data were then rescanned and placed within the appropriated theme. At this point, the VOI data were analyzed using the procedure described previously. The third stage consisted of a comparison of learning goals, rationale, and student perspectives across the data categories (field notes, interviews, and the VOI). Themes with integrity across data categories in a given school were compared with the theoretical value-orientation literature to examine the theory as practiced. In the final step, commonalities and distinctions as reflected in the planning-teaching-learning process were compared.

\section{Results}

Teachers' perspectives on content selection represented a blend of value orientations within a value profile. Profiles were elaborated based on an understanding of the teachers' learning goals and expectations, the rationale for their content selections, and students' comprehension.

\section{Bill's Value Profile}

Bill taught in a multipurpose room at an elementary school where 364 students were enrolled. During the gymnastics unit, the room was filled with mats and equipment. Bill had been a gymnast and often demonstrated skills for his students. His lesson for third, fourth, and fifth graders began with flexibility 
warm-ups, and students were directed to focus on the muscle or limb being stretched. He often drew pictures of the stretching positions on the blackboard or used an overhead projector to show correct body positions on the wall. His skill instructions were detailed, with an emphasis on the specific body positions necessary for successful performance. He worked individually with students to assist in modifying their performances based on his feedback:

Bill is teaching the third-grade class to perform cartwheels. He is walking from mat to mat assisting students to position their hands on the floor and lift their hips as they turn. He stops the class and suggests, "A cartwheel is like a bicycle wheel. The arms and legs are like wheel spokes. Once you spring off the mat the hand, hand, foot, foot positioning is done to an even beat. Your arms and legs are wide apart like the wheel spokes." He asks two girls to perform cartwheels slowly while he emphasizes the evenness and positioning of the "spokes." He encourages everyone to try again. (Field notes)

Bill appeared to focus completely on the skill he was teaching. He gave specific and detailed descriptions of skill components, breaking each skill down for analysis and practice.

Class observations suggested that some students, especially the boys, often became distracted and did not pay attention to Bill's descriptions or follow his directions:

Jed and Tom are punching and pushing each other near the parallel bars. Bill continues to demonstrate handstands, emphasizing specific cues for weight transfer from the floor to the inverted position. Jed tackles Tom, and they land on the mat with a loud smack. Bill looks up but continues to describe the practice drill for the handstand. The boys stop and listen to the directions for practice and are back on-task as the practice session begins. Bill does not speak to them but continues to provide skill feedback as he walks around the room. (Field notes)

Although Bill often ignored off-task behavior, he was quick to reward and reinforce children who listened and followed directions. He appeared concerned that all children were practicing the skill and encouraged students who had improved, even though they had not yet mastered the skill. Bill explained his curricular aim thus:

I want for them as people a confidence in performance, a multiexperiential kind of thing, so when they go to middle school they will be able to move as efficiently as they can. They need to have the raw materials that make skills. (Interview)

Bill spent a large proportion of class time discussing skills. There was a strong emphasis on disciplinary mastery and learning process in the class demonstration and the use of specific skill-oriented feedback. The information was technically oriented, with a focus on specific cues for enhanced performance. Much less time was devoted to social goals or to efforts to make the content personally meaningful to students. Bill was often so focused on the teaching and learning process associated with skill and fitness development that he chose not to comment on off-task behavior because he said it detracted from the performance 
cues he wanted to emphasize. Bill rarely disciplined students by having them sit out, arguing,

When students sit out they are not involved with the skills that I am teaching. There is no way that they can learn if they are not practicing. If someone deliberately tries to hurt someone else physically, I will make them sit out, but that is the only time. (Interview)

At times off-task behavior became disruptive, distracting other students from the task. In these instances, Bill spoke patiently to the offending students, either asking them to move where they could work effectively or moving them to a space near where he was demonstrating. He did not derive social or individual "teachable moments" from discipline problems but quickly refocused the class on the skill or fitness objectives.

Interviews with students suggested they understood the importance of skill and fitness development. One third-grade boy said, "We have to use our mind. Like in basketball, we have to learn where we should stand and what angle we should throw at.' A fifth-grade boy responded,

We learn the right way to play soccer, and in tumbling we learn how not to hurt ourselves. He teaches us stuff we will use later. Each year he just adds more and more so that now we are the best in our school.

When asked what he learned in physical education, a third-grade boy said, "How you get fit, stay healthy, and stay in shape.' These data were similar to those learning process (DM/LP) paired value orientation. Students in these classes

Bill's VOI scores, reported in Figure 1, indicated strong support for the traditional disciplinary mastery $(\mathrm{DM})$ knowledge base $(T$ score $=36.37)$. Although he ranked items in the learning process (LP) and the self-actualization (SA) categories as consistently important, his $T$ scores ( 40.30 for SA, 42.31 for LP) were not sufficiently low (indicating a high priority on the VOI) to reach the cutoff scores that would indicate a high priority for the LP (37.9) and SA (37.35) orientations. Bill consistently ranked the ecological integration (EI) and social reconstruction (SR) items as low priorities (83.29 and 70.15, respectively). Thus, Bill's VOI profile suggested that he promoted the importance of the knowledge base in physical education with concomitant concern for student learning needs, but he did not support curricula that encouraged social reform and responsibility. Bill's program exemplified an emphasis on traditional sport, skill, and fitness content in physical education. This focus was so strong that only the most disruptive off-task behavior caused him to veer from his skill-oriented objectives. When Bill was asked about behavior problems in his classes, he responded that he would like students to work more cooperatively but that he had tried several strategies unsuccessfully. He believed that if the content was exciting, most students would pay attention.

\section{Dave's Value Profile}

Dave taught in an elementary school with an enrollment of 631 students. Two teaching stations, a newly constructed gym and a multipurpose room, were available 


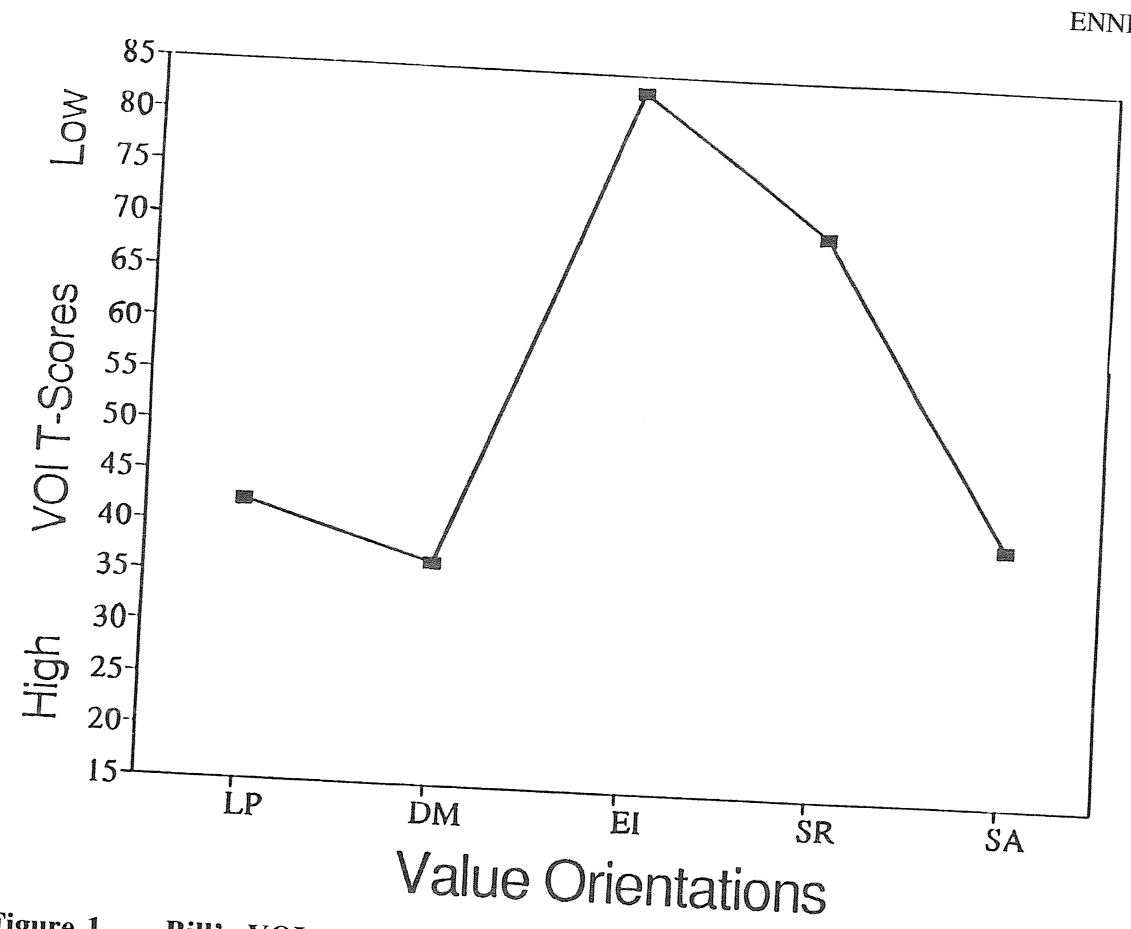

Figure 1 - Bill's VOI profile.

for instruction. Although there was another physical educator assigned to the school, they rarely team-taught except when working with classes of special education students. The principal and classroom teachers described Dave as a "warm, charisand praised and disciplined students enthusiastically about the activities each day suggested that he had few discipline with equal effectiveness. Class observations asked to sit out because they hadine problems; occasionally, though, children were

Dave included they had not listened or followed directions.

about every $10-15$ minutes. He explained in each class, shifting to a new activity changes increased students' motivationed in an interview that frequent content his class to be boring, and he divation and interest in the class. He did not want much it will be boring - monoton't want to get bored. "If I do something too different activity every 10 to the observations suggested to 12 minutes just to keep things going." Data from 45 -minute period. Classes combined different activities were taught during every and scooter or parachute games. activity, emphasizing the skill cues necess each segment, Dave explained the aged to follow directions and work spary for success. Students were encourexplained his rationale for shorter units: specifically on the required task. Dave

I tend to do areas four times a year rather than once. Before [I changed to this format], I would do one long jump rope unit, while now I will do each [the content is] spread out week. I think students tend to learn more when 
relate things better now than I used to. I think more about what activity or skill carries over from one unit to another. I am giving more thought to how well things correlate from one activity to another, and I am better at pointing out how things like hand-eye coordination carry over from soccer to basketball to so many sports that we do. (Interview)

Observations suggested that Dave worked to create a supportive social environment where the students learned to assist each other and offer supportive comments even when their team was not successful. He purposely placed young students under pressure in competitive situations while instructing them in strategies to handle adversity. He reminded students that "you had to make a mistake eight or nine times before you should expect to get better" (field notes). Of special interest was the class jump rope competition. The final class activity during the jump rope unit was to run into a long turning rope, jump once, and run out the other side. All students in the class participated, forming one long line beside the turning rope. Each person scored 1 point for a successful jump. The contest ended when a student failed to complete the task successfully. The score for each class was written on the board. Student eagerly compared their daily score with other classes' scores.

At the beginning of each competition, Dave identified four captains and asked them to assess their classmates' skill levels and to arrange them in line with the most skilled jumping first. This strategy was used to maximize the class score. If a captain asked a classmate to move farther down the line, Dave explained, "You should not take it personally, the person is just trying to do the best for the team" (field notes). Dave reminded the students that at some point someone was going to miss and that it was appropriate to say, "Nice try" and give them a high five. It was the children's responsibility to practice at lunch; the best jumpers were to help those not as skilled so the class team would be more successful:

You want to help the students who are having the most trouble. In any activity there are people who are stronger and weaker and that will change for every activity. So you want to help people in your group so that your class will score higher. (Field notes)

In discussing the jump rope competition, Dave emphasized the importance of competition for elementary school students:

There needs to be some competition. It is there in life along with the team concept. Not only do I want them to win, but I also want them to be successful in the way they treat each other. After they go through the competition a few times, even when someone missed there was a lot of support. On the one hand, it was hard for them because they wanted to win. But it was more important to make the student who missed feel better, even if our team didn't win. The students in the class come together-maybe for the first time this year. (Interview)

In interviews, students in Dave's classes appeared to understand the importance of supporting others. A third-grade girl suggested that "it was important to respect other people and not get upset when someone on your team makes a mistake. You should try to help them out." A fourth-grade boy said that it was important to be a good team member. When asked to explain, he said, "To cooperate with your team and be friends and help them if they don't know how to do something. I helped in basketball. I helped someone with a lay-up.' Other students appeared to focus 
on the learner emphasis in Dave's classes. One fourth-grade girl said, "He wants you to respect yourself, first. To do the best you can. If you can't do it, still try your hardest." A fifth-grade girl pointed out that team captains had a special responsibility to "listen to everybody when they talk about their feelings and they have different ideas. Respect their opinion, and do what they want you to do."

Dave's VOI profile, presented in Figure 2, indicated that he placed a high priority on the EI (41.37) value orientation and a low priority on the other four orientations (61.69 for DM, 46.93 for SA, 57.91 for LP, and 60.33 for SR). His priority on the EI orientation suggested that he believed in a balanced emphasis between the role of the learner, the context, and the content and helped students to prepare for the future. None of the $T$ scores was excessively high or low, confirming this balance in his rankings.

Dave's program reflected an emphasis on the social ecosystem in his classes. He emphasized that students' behavior toward others in stressful and exciting times was an important indicator of their development as people. Changes in activity were perceived as changes in context. Dave stressed the interdependence of class members in accomplishing class and team goals. He believed that change served both to keep the class interested and to enable students to perform effectively within a constantly evolving environment.

\section{Betty's Value Profile}

Betty taught in an elementary school of 621 students. She and a part-time colleague taught their classes in a full-sized gym. The walls of Betty's gym held

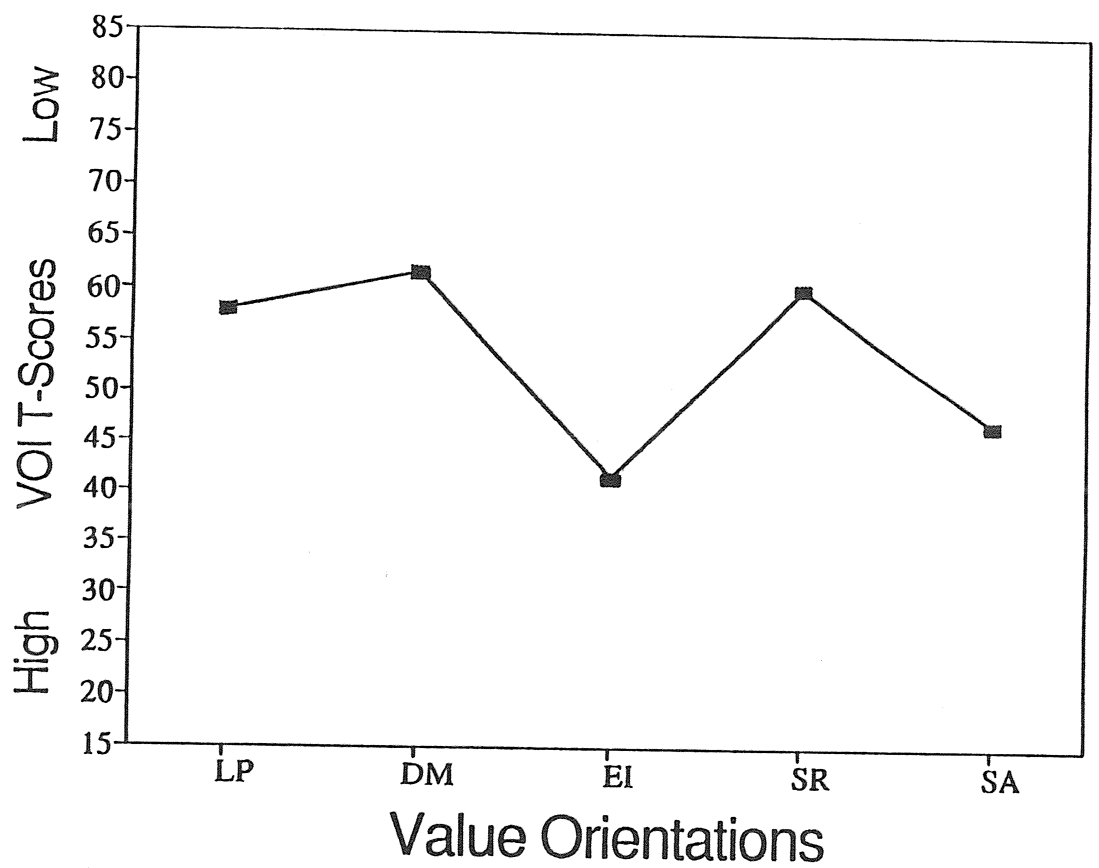

Figure 2 - Dave's VOI profile. 
posters for the "Happy Heart Club" and the "Magic Ball Skills Club.' Figures of Smurfs playing ball, jumping rope, and playing tag filled in spaces around life-size human figures with muscles and bones carefully outlined. The blackboard and wall charts were used frequently in writing tasks completed by the students. Betty was busy each morning preparing posters and wall charts for the activities to be discussed that day. Observations revealed that students were placed in situations where they had to cooperare in order to be successful. She specifically taught students how to assist others in the tumbling unit and how to solve disputes within their groups.

I carefully group students based on their ability to work with others, placing them in groups with friends when the task is challenging and organizing them in groups with students who have more difficulty working together when the task, itself, is not demanding. I often ask students involved in small-group activities about how they are cooperating or suggest strategies to help them achieve group goals more effectively. I try to end the class with a group discussion of content likes and dislikes, emphasizing that everyone will enjoy the class if we help each other. (Interview)

Each cooperative task involved skills or fitness knowledge as the means to cooperation and social responsibility. Although cues associated with skills and fitness were frequently given, the major focus was developing cooperation and respect for other students and the teacher. Betty's disciplinary comments and actions emphasized that disruptive or off-task behavior did not help the group achieve, or the individual be successful at, the task. The goals of cooperation and respect were of such importance that Betty used them as key words in one instructional unit:

I want to bring the goals of cooperation and respect to the forefront of their minds. I want them to know through a number of experiences what it is and what it isn't. Each time they work with others, I want them to ask themselves whether this was done cooperatively and with respect for the other person's feelings. I try to show them both effective cooperation and noncooperation. I want to develop an awareness of the terms and what they mean and what effect they have on people and their feelings-not just identifying it, but what they can do to promote good cooperation between others and property. I test them by putting them in groups to find out if they are truly able to accept others and cooperate.

In order to teach content associated with the goals of student autonomy and social responsibility, Betty had developed a progression of cooperative principles that were incorporated in her task and station work regardless of the content. The principles were based on increasingly greater levels of student acceptance of each other, helping behaviors, and team orientation. The progressions were described by Betty as "levels":

- Level 1: Tasks that require the individual to cooperate with the teacher by not bothering anyone (e.g., taking turns, staying on task, and participating).

- Level 2: Tasks where students must work together to be considered successful. Students are involved as a group and must consider others' feelings, strengths, and weaknesses (e.g., pyramids, partner stunts, designing game strategies).

- Level 3: Tasks where one student performs and a second student changes 
roles to spot or make sure the environment is safe. Students must be concerned about others. Taking turns involves giving up personal participation time to assist others (e.g., designing safe movement patterns when several children are working in a limited space).

Students had mixed feelings about the unit on cooperation and respect. On the one hand, they were able to define the key concepts emphasized throughout the unit. One fourth-grade girl explained that cooperation meant that you "work with each other; if a person is having trouble doing a cartwheel or a handstand, she wants you to try to help them, and then if you are having trouble in something else then someone will help you." When asked what the teacher expected in class, a third-grade girl responded, "She really believes in you and that you can do everything as long as you try." A fifth-grade boy said, "We have a lot of fun in here, but she is going to ask you a lot of questions and sometimes she will ask you to stand up and tell the answer by yourself.' Other students were not as supportive of this unit. A fifth-grade boy said,

I don't like the setup that she just put us in. There were not a lot of friends in my group, but I realize that she is trying to do something new and that she wants us to be friends and learn to cooperate. I also don't like the way we always find a way to have a discussion at the end of class. This takes away from class time. She stresses learning a lot more than I would like.

Betty's VOI profile, reported in Figure 3, reflected a high priority for the SA (32.01) and SR (37.88) orientations and a low priority on the LP (55.07),

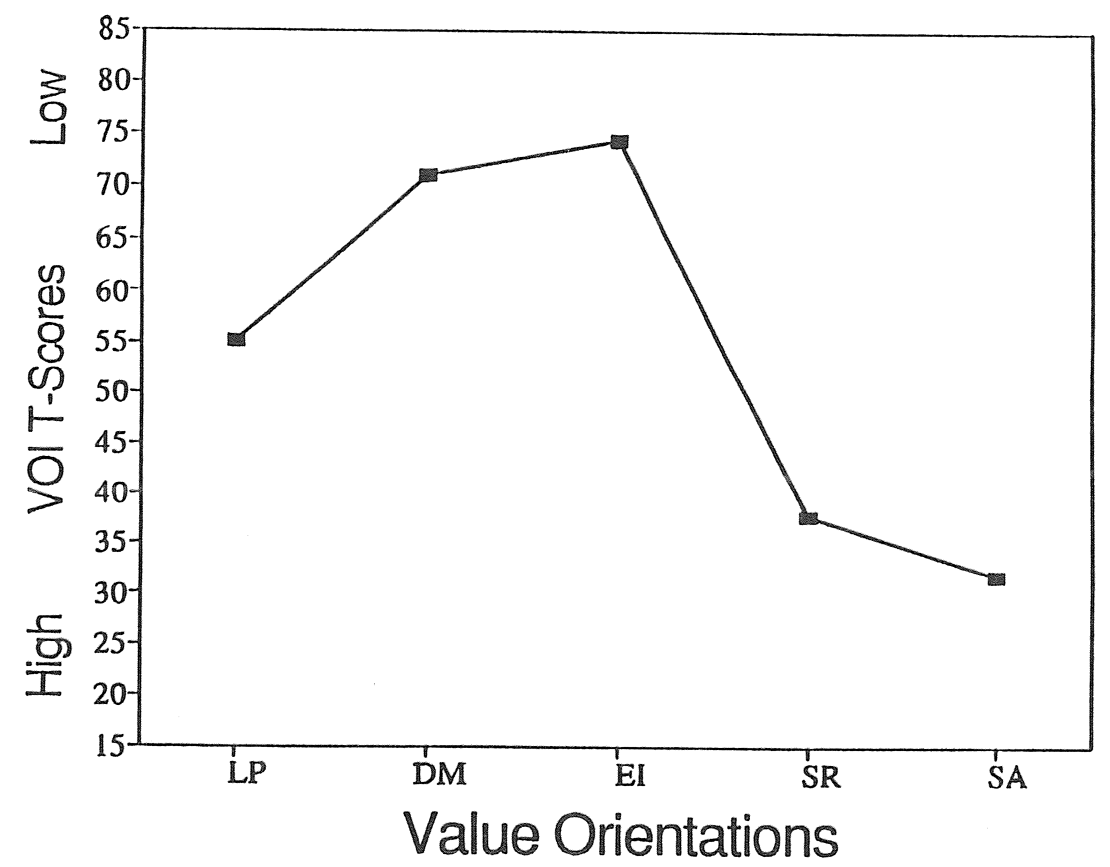

Figure 3 - Betty's VOI profile. 
DM (71.03), and EI (74.24) orientations. She strongly favored the studentoriented SA perspective but appeared to temper it with a concern for the child's place within society as reflected through social responsibility and respect for others. According to her scores on the VOI, she minimized the role of the traditional knowledge base (DM) and learning process (LP) values and did not emphasize a balanced perspective (EI).

Betty's emphasis on the SA/SR pair reflected the complex synthesis of value orientations that influenced her curricular decision making. Although she was competent to teach traditional physical education content (and her students were relatively skilled and fit), it was clearly not her priority. Instead, she explained that students must learn to cooperate and respect each other if they were to be successful in school and in life.

\section{Discussion}

Value profiles represent a blend of value orientation perspectives. The VOI affords the opportunity to examine the relative value that physical educators place on five theoretical value orientations. Because the VOI reflects a score on each perspective (rather than combining values into an overall mean), the integrity of each component of the profile is maintained. Teachers demonstrate a high or low priority by ranking items from a specific orientation consistently across the 15 sets. The VOI, however, represents an ideal perspective, minimally affected by the limitations of context.

It is more difficult to disentangle a teacher's value orientation priorities in an operational setting. The ideal curricular and instructional decisions must often be changed or adapted to accommodate the constraints within the teaching setting (Clark \& Peterson, 1985). Because teaching occurs within a complex network of relationships similar to an ecosystem, various factors support and constrain the planning-teaching-learning process. When resources such as time, energy, and money are devoted to one aspect of the system, other components must compensate. In physical education, the scarcity of these commodities often results in the emphasis on a few critical content components at the expense of other equally viable alternatives.

Both the ideal and the practical perspective are required to understand the curricular decision-making process. The ideal priorities reflect the teacher's preferred mode of operation and thus provide a set of targeted educational goals. Conversely, the operational constraints dictated in the real setting require a set of compromises from the ideal that may or may not be educationally acceptable. Value orientations are hypothesized to be influential in curricular decision making to the extent that they are not constrained by factors that shift the environment from one of learning to one of custodial care. The differences between the teacher's preferred curricular goals and his or her operationalized objectives can provide insight into the power of contextual constraints within the educational ecosystem.

Dynamical systems or chaos theory can provide insight into constantly changing and evolving ecosystems (Crutchfield, Farmer, Packard, \& Shaw, 1986). The theory elaborates a framework of critical components hypothesized to influence both intermediate and long-term decisions. When this model is applied to educational ecosystems (i.e., Cziko, 1989; Sawada \& Caley, 1985), learning 
is thought to be influenced by a few strong attractors acting within various learner, instructional, and contextual constraints. Attractors are major, controlling variables that influence or attract surrounding elements or behaviors. One or two strong attractors may be responsible for a series of outcomes that cascade through education systems. In physical education, attractors such as the teacher's management style may determine student groupings and interactions throughout the unit. For instance, by choosing to organize students in teams by ability groups, the quality and frequency of future interactions and practice opportunities for both skilled and unskilled students will be predetermined.

When physical education programs or classes are viewed as dynamical systems, value orientations may be conceptualized as strong attractors within the planning-teaching-learning process (Ennis, 1992). When value orientations are monitored under ideal conditions (without constraints), we can determine the strength or priority of the value attractor to influence curricular and instructional decisions in the program. We may know, for instance, that a teacher would give priority to social interactions in the classroom and use traditional skills and fitness content as a means of providing opportunities for positive interactions. In reality, however, state or school district mandates regarding fitness testing can constrain the teacher's ideal plan. Because fitness scores by class and school are reported to the central office and then to the local newspaper, the teacher may feel obligated to spend class time on teacher-directed individual activities that develop fitness capacity quickly and efficiently. The issue is not whether social interaction is an inherently more valuable goal than fitness development but that the teacher felt constrained by external factors and chose not to implement the preferred content goals.

In this research, the ideal preferences documented in these three teachers' VOIs were at times operationalized and constrained by the environment where they worked. Bill's profile (see Figure 1) suggested a high priority on disciplinary mastery, learning process, and self-actualization and a low priority on the ecological integration and social reconstruction orientations. If the high-priority orientations are viewed as bowls or basins that collected other teaching behaviors, it is not surprising that Bill's interactions with the children included a strong emphasis on specific skill feedback, frequent teacher and student demonstrations of the "right" way to perform, and a belief that all students required skills to enjoy participation in physical activity throughout their lives. In dynamical systems theory, the low-priority orientations could be conceptualized as weak attractors that had little or no control over curricular decision making. Bill was not directly concerned with social interactions or access to equal opportunities except when it facilitated skill acquisition.

Bill's preference for a skillful movement curriculum was constrained by factors within the educational ecosystem that limited his ability to teach and his students' opportunities to learn. Under ideal circumstances, Bill's VOI scores indicated his preference that students practice and learn skills and enjoy opportunities to perform them. Although numerous examples were documented of the skill focus in his class, disruptive students at times constrained the learning environment to the extent that Bill could not teach. The disciplinary mastery attractor may have limited his willingness to divert skill time to class management. He hoped to spend the majority of class time on skills and was disappointed when he was distracted from these tasks. 
Dave's value profile (see Figure 2) suggested a high priority on ecological integration, demonstrated as a balanced perspective between the learner, context, and content. His value preferences were conveyed through a series of strategies that emphasized the interrelatedness of these three key elements. Dave nurtured students to work intently and to enjoy the class. He emphasized the importance of learning content for the purpose of helping others and the role of each student in contributing to the group effort. Although many of Dave's individual teaching strategies could be identified and labeled within the literature (i.e., Mosston \& Ashworth, 1986), the essence of the ecological integration orientation was conveyed in the way he presented the curriculum as a balance of integrated elements. No single topic or method, alone, could communicate this message. Instead, both the teaching strategies and the curriculum content were integrated and interdependent, suggesting that it, too, was a form of educational ecosystem.

The constraints in Dave's environment were much less obvious. He had taught at the school since it had opened and had the freedom to schedule units and content as he chose. The other physical education teacher agreed to work within his curriculum. Because he managed students well and matched the content difficulty to students' abilities, learner characteristics did not appear to constrain his teaching. Likewise, he taught in a new gym, with equipment for each student. When asked about constraints to his teaching, he mentioned the problem of insufficient time to cover content. He suggested, however, that "if you stay at a school long enough, you can create a great teaching environment" (interview).

Betty's value profile (see Figure 3) suggested that the social reconstruction and self-actualization attractors influenced many of her goals and objectives. She emphasized the importance of cooperation and respect for self and others throughout her lessons. She often stopped the activity to ask students how they were cooperating on the task. When questions about subject matter were asked, students who responded correctly gained a point for their team or group. It was interesting to note that, although Betty's VOI profile indicated a low priority for the disciplinary mastery and learning process orientations, students in her classes were able to perform various skills without difficulty. Skills were used as a means to the end of group cooperation and personal satisfaction. Betty used skills and fitness activities as a way to practice group cooperation and as a means through which students gained pride in their accomplishments. Although disciplinary mastery was a relatively low priority, the instrumental skill and fitness goals accomplished on the way to cooperation resulted in skillful movement.

Betty also felt constrained by the context in which she taught. In her interview, she stated goals consistent with each of the value orientations. She indicated, however, that she did not have adequate time to teach students all the content goals she believed important. She argued that although physical education should be synonymous with skill and fitness development, the limited time allotted to physical education required that she weigh carefully each topic and select only those that were most important to her students. She stated that her students could learn skills and sport in youth leagues but must be taught to cooperate in school. Unless students felt good about themselves and could cooperate with each other, they would not be able to learn skills and fitness content.

Value orientations can be viewed as one of several strong attractors that influence the curricular decision-making process in the school ecosystem. In 
ideal situations, the value attractors can influence decisions related to content selection and implementation. When value orientations are examined within an educational ecosystem, their influence may be constrained by the characteristics of the learner, the instructional environment, and the social context. The extent to which the teacher implements specific learning goals may be related to the strength or weakness of the value attractors influencing the process. Research is needed to define additional attractors within the educational ecosystem and to examine the realm of behaviors influenced by each attractor. If value attractors and their concomitant constraints are better understood in both ideal and operational settings, it may be possible to identify and ameliorate the most critical constraints to the learning process.

\section{References}

Apple, M.W. (1982). Education and power. Boston: ARK.

Bloom, B.S. (1981). All our children learning. New York: McGraw-Hill.

Brunner, J.S. (1960). The process of education. Cambridge, MA: Harvard University Press.

Clark, C.M., \& Peterson, P.L. (1985). Teachers' thought processes. In M.C. Wittrock (Ed.), Handbook of research on teaching (pp. 255-296). New York: Macmillan.

Colwell, T. (1985). The ecological perspective in John Dewey's philosophy of education. Educational Theory, 35, 255-266.

Crutchfield, J.P., Farmer, J.D., Packard, N.H., \& Shaw, R.S. (1986, December). Chaos. Scientific American, pp. 46-57.

Cziko, G.A. (1989). Unpredictability and indeterminism in human behavior: Arguments and implications for educational research. Educational Researcher, 18(4), 17-25.

Dewar, A.M. (1987). The social construction of gender in physical education. Women's Studies International Forum, 10, 453-466.

Dewey, J. (1916). Democracy and education. New York: McMillan.

Eisner, E.W., \& Vallance, E. (Eds.) (1974). Conflicting conceptions of curriculum. Berkeley, CA: McCutchan.

Ennis, C.D. (1992). Reconceptualizing learning as a dynamical system. Journal of Curriculum and Supervision, 7, 115-130.

Ennis, C.D., Chen, A., \& Ross, J. (1992). Educational value orientations as a theoretical framework for experienced urban teachers' curricular decision making. Journal of Research and Development in Education, 25, 156-163.

Ennis, C.D., \& Hooper, L.M. (1988). Development of an instrument for assessing educational value orientations. Journal of Curriculum Studies, 20, 277-280.

Ennis, C.D., Mueller, L.K., \& Hooper, L.M. (1990). The influence of teacher value orientations on curriculum planning within the parameters of a theoretical framework. Research Quarterly for Exercise and Sport, 61, 360-368.

Ennis, C.D., Ross, J., \& Chen, A. (1992). The role of value orientations in curricular decision making: A rationale for teacher's goals and expectations. Research Quarterly for Exercise and Sport, 63, 38-47.

Ennis, C.D., \& Zhu, W. (1991). Value orientations: A description of teachers' goals for student learning. Research Quarterly for Exercise and Sport, 62, 33-40.

Freire, P. (1970). Pedagogy of the oppressed. New York: Continuum.

Franck, M. (Chair) (1991). Physical education outcomes: Report to the NASPE Cabinet. Reston, VA: National Association for Sport and Physical Education. 
Goetz, J.A., \& LeCompte, M.D. (1984). Ethnographic and qualitative design in educational research. Orlando, FL: Academic Press.

Griffin, P.S. (1985). Teacher perceptions of and responses to sex equity problems in a middle school physical education program. Research Quarterly for Exercise and Sport, 56, 103-110.

Hellison, D.R. (1985). Goals and strategies for teaching physical education. Champaign, IL: Human Kinetics.

Hicks, L.E. (1970). Some properties of ipsative, normative, and forced-choice normative measures. Psychological Bulletin, 74, 167-184.

Jewett, A.E., \& Bain, L.L. (1987). The purpose process curriculum framework: A personal meaning model for physical education. Journal of Teaching in Physical Education, 6, 195-366.

Jewett, A.E., \& Ennis, C.D. (1990). Ecological integration as a value orientation for curricular decision making. Journal of Curriculum and Supervision, 5, 120-131.

Jewett, A.E., \& Mullan, M.R. (1977). Curriculum design: Purposes and process in physical education teaching-learning. Reston, VA: American Alliance of Health, Physical Education, Recreation and Dance.

Kilpatrick, W.H. (1918). The project method. Teacher's College Record, 19, 319-335.

Kliebard, H.M. (1987). The struggle for the American curriculum: 1893-1953. New York: Routledge \& Kegan Paul.

Kliebard, H.M. (1988). The effort to reconstruct the modern American curriculum. In L.E. Beyer \& M.W. Apple (Eds.), The curriculum: problems, politics and possibilities (pp. 19-31). Albany, NY: State University of New York Press.

Lawson, H.A., \& Placek, J.H. (1981). Physical education in secondary schools: Curriculum alternatives. Boston: Allyn \& Bacon.

Maslow, A.H. (1979). Humanistic education. Journal of Humanistic Psychology, 19, 1327.

McNeil, J.D. (1985). Curriculum: A comprehensive introduction. Boston: Little, Brown.

Mosston, M., \& Ashworth, S. (1986). Teaching in physical education. Columbus, OH: Merrill.

Papert, S. (1980). Mindstorms: Children, computers and powerful ideas. New York: Basic Books.

Rink, J.E. (1985). Teaching physical education for learning. St. Louis: Times Mirror/ Mosby.

Rogers, C. (1983). Freedom to learn. Columbus, OH: Merrill.

Sawada, D., \& Caley, M.T. (1985). Dissipative structures: New metaphors for becoming in education. Educational Researcher, 14(3), 13-19.

Siedentop, D., Mand, C., \& Taggert, A. (1986). Physical education: Teaching and curriculum strategies for Grades 5-12. Palo Alto, CA: Mayfield.

Spencer, H. (1860). Education: Intellectual, moral and physical. New York: Appleton.

Steinhardt, M.A. (in press). Healthy pleasures: A new paradigm for promoting wellness behavior. Proceedings of the Seventh Curriculum Theory Conference in Physical Education. 